

\section{Un arte disensual a partir de Jacques Rancière}

\section{Artículo de reflexión}

Recibido: 19 de febrero de 2018

Aprobado: 5 de marzo de 2018

\section{Angélica González Vásquez}

Universidad Nacional de Colombia, Colombia

angmgonzalezvas@unal.edu.co

Cómo citar este artículo: González Vásquez, Angélica (2018). Un arte disensual a partir de Jacques Rancière. Estudios Artísticos: revista de investigación creadora, 4(5) pp. 192-205. DOI:https://doi.org/10.14483/25009311.13493

Jacques Rancière (2009), Et tant pis pour les gens fatigués: entretiens, París: Éditions Amsterdam.

\section{Resumen}

A partir de las teorizaciones del filósofo francés, Jacques Rancière, en este ensayo se indaga la relación entre arte y política, particularmente a través de nociones tales como "interrupción", "irrupción" o "disenso". Lejos de entender arte y política como realidades separadas, se busca encontrar hilos de conexión y de tensión en donde cada espacio contiene sus propios principios de acción y de manifestación. Tomando elementos esenciales de la reflexión del filósofo francés, en el escrito se aborda la posibilidad de pensar el "nudo" polémico por el cual arte y política, en su propia especificidad, redistribuyen lo "sensible" de una comunidad, hacen visibles los sujetos y los objetos que antes no eran contados como partes; esto llevará en la parte final a reflexionar sobre las políticas actuales del arte posutópico.

\section{Palabras clave}

Disenso, arte, política, estética, Jacques Rancière.

\section{A Dissensual Art Based on Jacques Rancière}

\footnotetext{
Abstract

Based on the theories of the French philosopher Jacques Rancière, this essay explores the relationship between art and politics, particularly in notions such as "interruption", "irruption" or "dissensus". Far from understanding art and politics as separate realities, we seek to find threads of connection and tension in which each space contains its own principles of action and manifestation. Taking the essential elements of the thought of the French philosopher, the paper addresses the possibility of thinking the controversial "knot" by which art and politics, in their own specificity, redistribute
} 
the "sensitive" element of a community, and make visible subjects and objects that were not counted before. This will lead, in the final part, to reflect on the current policies of post-utopian art.

\section{Keywords}

Dissent, art, politics, aesthetics, Jacques Rancière.

\section{Un art dissensuel à partir de Jacques Rancière}

\section{Résumé}

Basé sur les théories du philosophe français Jacques Rancière, cet essai explore la relation entre l'art et la politique, en particulier dans des notions telles qu' « interruption », « irruption » ou « dissidence ». Loin de comprendre l'art et la politique comme des réalités distinctes, nous cherchons à trouver des fils de connexion et de tension dans lesquels chaque espace contient ses propres principes d'action et de manifestation. Prenant les éléments essentiels de la réflexion du philosophe français, l'article aborde la possibilité de penser le « nœud » controversé par lequel l'art et la politique, dans leur propre spécificité, redistribuent le « sensible » d'une communauté, en rendant visibles sujets et objets qui n'ont pas été comptés comme parties auparavant. Cela conduira, en dernière partie, à réfléchir sur les politiques actuelles de l'art post-utopique.

\section{Mots clés}

Dissidence, art, politique, esthétique, Jacques Rancière.

\section{Uma arte dissensual a partir de Jacques Rancière}

\section{Resumo}

A partir das teorias do filósofo francês Jacques Rancière, este ensaio se indaga sobre a relação entre arte e política, particularmente em noções como "interrupção", irrupção" ou "dissenso". Longe de entender arte e política como realidades separadas, procura-se encontrar fios de conexão e tensão nos quais cada espaço contém seus próprios princípios de ação e de manifestação. Tomando elementos essenciais da reflexão do filósofo francês, o artigo aborda a possibilidade de pensar o polêmico "nó" pelo qual arte e política, em sua própria especificidade, redistribuem o "sensível" de uma comunidade, tornam visíveis os sujeitos e os objetos que antes não eram considerados como partes; isto levará à reflexão, na parte final, sobre as políticas atuais da arte pó-utópica.

\section{Palavras-chave}

Dissenso, arte, política, estética, Jacques Rancière.

\section{Sug rurai kawachiku Jacques Ranciere}

\section{Maillallachiska}

Parlaku sug iacha runa suti Jacques Ranciere kai mailla kilkapi kawachispa karumanda Nukanchipa kausai Maskaspa nukanchi kikin munanakungapa imasapas llukanchimi ñugpasinama llugsinga maituku atun chaka tiaskapi llukanchimi allimanda ialispa ikuti allimanda imapas purei kallaringa.

\section{Rimangapa Ministidukuna}

Kawai ima rurangapa, rurai, chimanda rimai, nukanchi kikin kawai Jacques Ranciere chasa suti runa.

***

Una distancia que parece a menudo insuperable se presenta cuando un término definido dentro del dominio teórico se contrasta con su uso práctico. Es el caso de la diferencia entre la idea de política que se intenta construir en la filosofía y aquella que practican los políticos y que se condensa, solo en parte, dentro del derecho más tradicional. Sin embargo, esta divergencia no puede ser del todo comprendida como una oposición radical: ella expresa una relación - o una alternativa - tras la cual precisamente un nuevo pensamiento o una acción pueden surgir. En efecto, es necesario que el concepto de lo político se aproxime a esta praxis de la política, aunque también es necesario que mantenga una cierta distancia crítica.

Se puede constatar la misma distancia cuando nos aproximamos a la noción de arte que nos propone la filosofía y las prácticas creativas de los artistas. Es fácil constatar que las teorizaciones sobre el arte que se construyen desde la filosofía o la teoría del arte, a menudo se apartan de lo que sucede en el mundo del arte. Esta distancia no supone la incapacidad del filósofo o del esteta para comprender 
qué hacen los artistas, sobre todo en el arte contemporáneo, ni una falta de claridad de las propuestas que los artistas realizan. Tanto las prácticas de los artistas necesitan ser pensadas a partir de un concepto o una teoría, como la filosofía naturalmente escoge al arte como uno de sus objetos de reflexión. Podemos entonces afirmar que la filosofía más que interpretar el arte piensa con él.

Esta relación entre el arte contemporáneo y la teoría se deja ver en momentos decisivos. Pensamos por ejemplo, en toda la discusión sobre la validez o invalidez del arte contemporáneo, sobre sus críticas y sus fervientes adeptos; sobre su relación con la sociedad o por el contrario su separación. Todas estas cuestiones aparecen en el terreno de la discusión en las últimas décadas y pueden ser puestas, a su vez, en el marco de la relación arte y política, sobre la traza conflictiva y cambiante de esta relación.

Tomemos dos casos relacionados con las formas de politización del arte que hacen evidente pensar en este vínculo y su transformación. A finales de los años 70, momento de la crítica institucional, artistas como Marcel Broodthaers, Martha Rosler, Andrea Fraser, Daniel Buren, Hans Haacke o Michel Asher, a través de sus declaraciones teóricas o de sus intervenciones artísticas, tanto en espacios abiertos, como al interior de instituciones culturales, buscaban producir una crítica de denuncia sobre las inequidades en las estructuras del mundo social y económico, también sobre las lógicas de poder que imponen las instituciones culturales sobre la producción artística. El otro ejemplo, sería aquel nombrado por el teórico del arte Marc Jiménez como La querella del arte contemporáneo (2010) que consistió, durante los años 90 , en las posiciones que adoptaron una serie de adversarios del arte contemporáneo quienes parecían tomar la palabra de un público poco familiarizado con las producciones artísticas que supuestamente manifestaba un rechazo y una incomprensión. Es claro que este enfrentamiento no sucedió de manera abierta, sino se dio en los espacios de las revistas especializadas de arte, en donde una parte de la institución artística intentaba legitimar su política de exhibición y la forma como distribuían sus recursos. De otra parte, los adversarios del arte contemporáneo defendían a un público que debía ser informado sobre las transformaciones de los modos de hacer arte, lo que llevó a algunos cambios y a la necesidad de reformar los programas de mediación de algunas instituciones de arte contemporáneo.

Este tipo de polémicas dejan preguntas que creemos fundamentales sobre el arte -y sobre la política - puesto que, a nuestro modo de ver, es necesario superar las posturas simples en el arte contemporáneo - o en la política actual-y tal vez intentar, como propone el filósofo Jacques Rancière, pensar esta relación entre el arte y la política no como realidades separadas en donde cada espacio contiene sus propios principios de acción y de manifestación, sino que es posible pensar su "nudo" polémico y así, cada uno - arte y política-, en su propia especificidad, redistribuyen lo "sensible" de una comunidad, hacen visibles a los sujetos y los objetos que antes no eran contados como partes.

Poner la cuestión en términos de "nudo" o de un "encuentro" y no de un universal dado, significa, de una parte, abandonar las respuestas unívocas y de otra parte, poner las preguntas en términos de una "paradoja", un "conflicto" o una "aporía"(Rancière, 1996). Al respecto, Rancière toma distancia de la etiqueta de filosofía política, pues no considera que ella exista como rama natural de la filosofía (Rancière, 1996). Retomando la tradición clásica que comienza con Platón, los filósofos han buscado eliminar el elemento de polémica o de desorden. Según Rancière, el desacuerdo en la política es precisamente el que permite la división y redistribución de las partes de lo que es común. Este elemento de disenso es precisamente la distancia entre un orden policial establecido y la fuerza de irrupción que viene cada vez a cambiar el orden precedente.

El camino que construye Rancière en su aproximación polémica de la política — y del arte — es aquel de la excepcionalidad más que la verificación de la regla. Para poner a prueba, aún hoy, un pensamiento diferente, el filósofo toma como estrategia la comparación de elementos sin ninguna conexión evidente creando así el choque de heterogéneos, es decir, la aceptación del suplemento en lugar de la verificación de las partes ya constituidas.

De este modo, la relación entre arte y política lejos de ser evidente, implica más bien ciertas 


\section{Jacques Rancière}

\section{La Mésentente}

Politique et philosophie

Jacques Rancière (1995), La mésentente: politique et philosophie, París: Éditions Galilée.

condiciones para comprender la manera en la que se da su encuentro. El arte político no existe como una rama natural de la historia del arte, tampoco puede ser simplemente asociado a un movimiento que pertenece a un contexto histórico específico. En efecto, en cada período de la historia, esta relación se presenta bajo formas muy particulares.

Durante los años 90, por ejemplo, era frecuente encontrar una crítica que señalaba la falta de compromiso del arte, en donde los artistas, supuestamente, no tenían otro interés que seguir las leyes del mercado, bajo el influjo de la política neoliberal (Maraniello, 2002). Este periodo marcado con la caída del muro y la reconfiguración del mercado global, en el caso de las prácticas artísticas corresponde a un momento en donde a menudo los artistas se replegaban sobre las formas

\section{Malaise dans l'esthétique}

\author{
Jacques Rancière
}

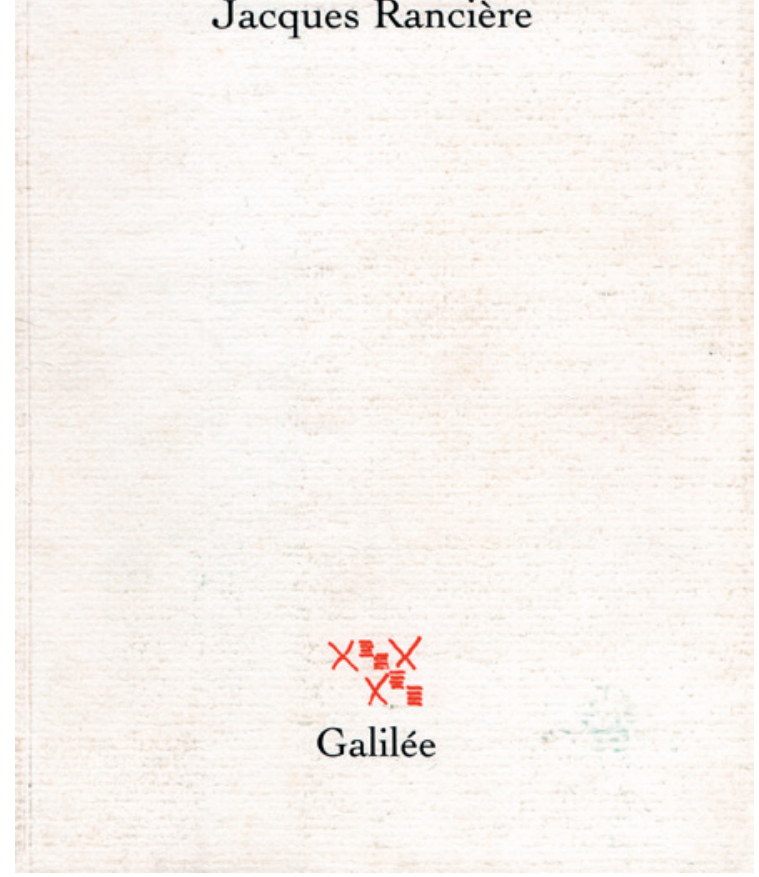

Jacques Rancière (2004), Malaise dans l'esthétique,

París: Éditions Galilée.

de presentación de la autobiografía a través de los relatos personales en exposiciones que abordaban las micropolíticas de la proximidad'. Era recurrente encontrar en las instalaciones artísticas las huellas de archivos propios, las fotografías de álbumes, los simulacros de habitaciones donde vagamente se escenifica la historia de un personaje real o inventado. Este tipo de obras serían los testimonios de la postura de los artistas que no parecerían seguir una ideología, ya no tenían un discurso militante en un movimiento y en donde solo, si acaso, es posible enunciar las formas de un arte político como una postura débil. El arte transformado en mercancía banal solo apuntaba a la celebración del mercado que podía solo acompañar la era de 
una democracia consensual y del individualismo. A la inversa, una década antes, se podrían situar las posturas opuestas en donde se sostenía que existía un lazo per se entre arte y política, reconociendo de manera simple que todo arte es político porque el arte comportaba una función social. El arte debería entonces cumplir diversos roles tales como ser reparador y podría así ofrecer ciertos principios de corrección ética.

Una vía alternativa a aquellas posturas supone decir que, tanto el arte como la política pueden ser percibidos como una suspensión o una interrupción de los roles habituales del gobierno o de la experiencia sensible normalizada. Esta caracterización de la política - y del arte- produce entonces formas de experiencia disensuales. Así, cada una de estas actividades, en determinados contextos y bajo ciertas circunstancias, redistribuye, por sus propios medios, lo sensible de una comunidad. Esto significa que tanto el arte como la política realizan bajo la figura de la interrupción, la redistribución de los roles que han sido asignados a las partes de una comunidad.

Tanto el arte como la política tienen una fuerza de irrupción que produce el disenso. En la reflexión de Rancière, el concepto de disenso no pertenece exclusivamente al dominio de la política, incluso si el conjunto de textos que incluyen este término se relacionan sobre todo con este dominio. Su traslado al campo del arte es, sin embargo, relativamente reciente Dissensus (Rancière y Corcoran, 2015). En el caso del arte, la irrupción del disenso es posible solo cuando se encuentra desligado de toda función específica y puede producir una experiencia estética que es también una experiencia de distancia en relación con un fin. Esta evidencia de pérdida de la función del arte aparece solo de manera paradójica en el momento en donde, a través de la vía de la estética, se diseña un proyecto más completo de reconciliación del hombre con su humanidad perdida. Dicho de otro modo, la tarea de la estética es precisamente aquella que reúne la razón y la sensación que habían permanecido separadas. De este modo, el arte puede ser una potencia singular de instauración sensible que resiste a las diferentes formas de dominación y de ejercicio del poder. El desafío que presenta el pensamiento de Jacques Rancière es que supone la búsqueda de un objeto polémico para pensar; es en este sentido que su trabajo opera también a través de la vía dialéctica, pero una dialéctica de la "brecha", del "intervalo" y de la "mezcla"2.

\section{Aisthesis de la política}

Es necesario volver brevemente sobre el hilo conductor de las investigaciones de Rancière, situando de un lado la teorización de la política en términos de conflictos entre mundos perceptibles y de otro, la teorización de la estética que se presenta en los términos de la ruptura y la repartición de lo sensible, es decir, en los términos de la definición de un campo de experiencia en ruptura con otros campos de experiencia posibles. Rancière (2000) señala que todo su trayecto intelectual está marcado por la cuestión que nombra la "repartición de lo sensible" como un espacio en donde se regula la percepción del mundo o se da la relación de una experiencia sensible en conexión con ciertos modos de interpretación inteligibles.

Lo anterior se enuncia en el terreno de la política en el texto El desacuerdo (1996) donde el filósofo francés, presenta la cuestión de la política en conflicto con la filosofía política. Así, la política no es un asunto dado, sino que es necesario cuestionarse cada vez: ¿cuándo hay política? Incluso si existen organizaciones del Estado, elecciones, partidos políticos, entre otros. La política aparece cuando existe la posibilidad de producir una serie de actos de enunciación que no han sido identificados en el campo de la experiencia; gracias a que estos actos aparecen o que un desacuerdo se manifiesta, es posible el cambio de todo el campo de la experiencia sensible. La política consiste entonces en introducir sujetos y objetos nuevos, en hacer visible aquello que no era, en escuchar seres que no eran dotados de palabra (Rancière, 1996). Es en este sentido que se puede pensar una praxis política como disenso y por ello, la reflexión sobre la política es paralela a una reflexión sobre la estética como experiencia de interrupción del espacio tiempo de lo común.

\footnotetext{
2 Aliocha Wald Lasowski, sitúa todo el trabajo de Rancière bajo la figura de la "brecha", nunca como una coincidencia o una identidad. (Game y Wald Lasowski, 2009).
} 


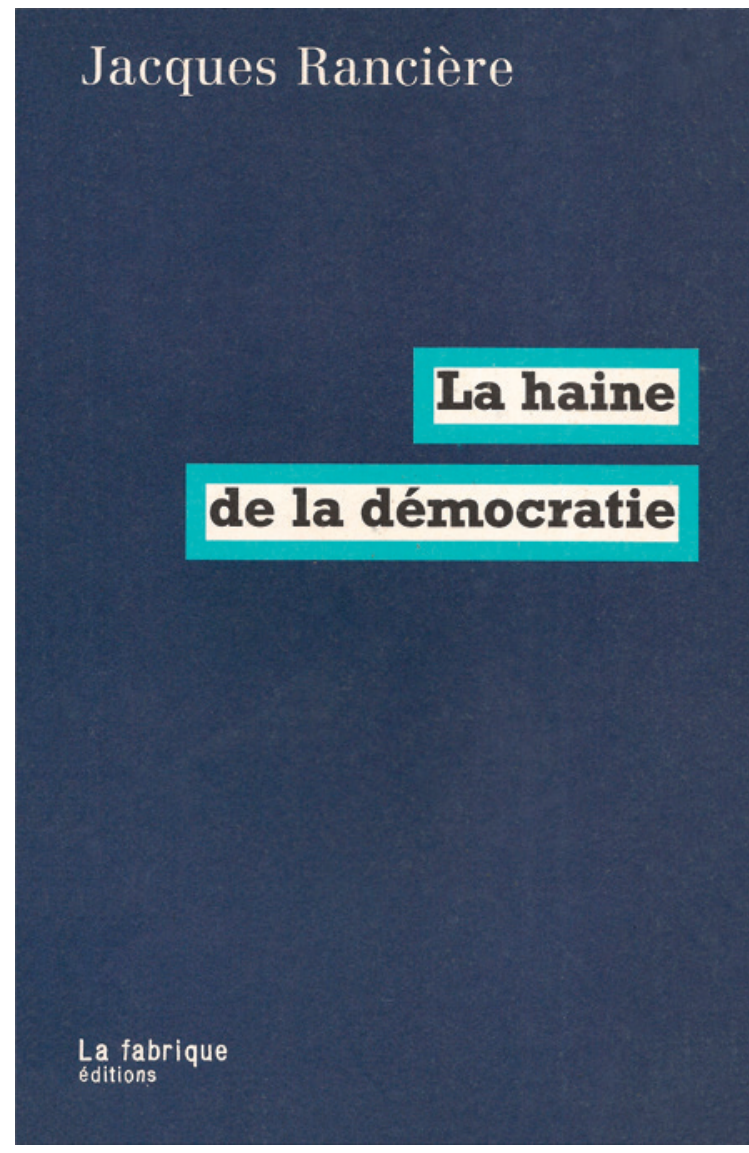

Jacques Rancière (2005), La Haine de la democratie, París: La fabrique

De otra parte, para Rancière la estética no es exclusivamente un discurso que pertenece al arte, ni una teoría del arte que muestra los modos de percepción de los objetos sensibles. Según su postura, este término aparece como manifestación de la ruptura al interior de formas destinadas a enmarcarse dentro de la institución de las bellas artes en la época moderna. La noción estética también convoca la manifestación de la separación entre las artes liberales y las artes mecánicas, una división que comporta la separación entre hombres de inteligencia y hombres de sensibilidad.

La estética no es entonces un discurso que oculta la diferenciación social entre los gustos de la alta cultura y aquellos de la cultura popular, como lo denuncia el sociólogo Pierre Bourdieu, sino manifiesta la capacidad de voz de "cualquiera" y su posibilidad para tener una experiencia estética (Rancière, 2009). La estética es así una cuestión

\section{Jacques Rancière}

\section{Le partage du sensible} esthétique et politique

La fabrique éditions:

Jacques Rancière (2000), Partage du sensible, París: La fabrique

política porque ella se refiere a la constitución de un mundo común y también porque produce rupturas:

Esta repartición de partes y de lugares se funda en un reparto de espacios, de tiempos y de formas de actividad que determina la manera misma en que un común se ofrece a la participación y donde los unos y los otros tienen parte en este reparto. (Rancière, 2000, p. 12)

Sin embargo, tanto la política produce descontento, como la estética genera un malestar que se manifiesta de manera recurrente a través de un odio generalizado tanto a la política como a la estética. Al respecto, Rancière señala que el odio de la democracia es la manifestación de un malestar que toca los aspectos más cotidianos de nuestra existencia, tales como la cohabitación y discusión con personas de creencias partidarias diferentes o las quejas sobre los malos funcionamientos de 
la seguridad social o, incluso, el descontento ante los aumentos injustificados de los precios que no se compensan con el salario, entre otros. El filósofo señala que este malestar político lleva el nombre de democracia: "es decir, el reino de los deseos ilimitados de los individuos de la sociedad de masas moderna" (Rancière, 2013, p. 7).

En el dominio de la estética, el malestar se manifiesta por la denuncia de un discurso engañoso que utiliza un cierto tipo de filosofía para ocultar el sentido último de las obras de arte y de los juicios críticos sobre el arte (Rancière, 2004, p. 9). Así, tanto en la política como en el arte se dan formas de encuentro y de tensión porque suponen nuevos lugares de asignación, así como la creación de otros discursos que no han sido normalizados. Es por ello que también atraviesan las disposiciones de los discursos hegemónicos y trabajan para producir nuevos objetos heterogéneos o nuevas voces dentro de un espacio social dado.

La política y el arte tocan lo sensible de una comunidad porque producen espacios de irrupción. La producción de estos nuevos lugares polémicos es lo que configura un territorio diferente tanto para la política como para el arte. Son territorios que permiten otra circulación "de modos de percepción, de nominación y de pensamiento del mundo que son disensuales en relación a los pensamientos dominantes" (Rancière, 2009).

\section{Políticas del arte}

La idea de una estética de la política es paralela a una política del arte. En el dominio del arte, a la pregunta: ¿cuándo hay arte? No podemos responder enumerando una serie de manifestaciones artísticas o indicando que hay arte porque existe un conjunto de instituciones que lo validan o porque un público asiste a una cantidad de eventos artísticos cada vez más espectaculares tales como exposiciones de todas las escalas, ferias de arte, bienales, entre otros. Esta discusión no se inscribe para Rancière en las polémicas sobre lo que la filosofía del arte dice que es el arte o indicando que las obras de arte son solamente un subconjunto de manifestaciones de lo sensible. La manera de pensar esta cuestión no toma la forma de una definición cerrada, sino se da, cada vez, en la consideración sobre las prácticas y los objetos artísticos a través de los diferentes espacios que conforman o disuelven pero que producen una experiencia estética significativa en la vida de una determinada colectividad.

Esta cuestión implica comprender la manera por la cual ciertas prácticas artísticas se manifiestan o se hacen visibles. Tanto para pensar el arte como para pensar la política, es necesario pensar cómo estas prácticas redistribuyen eso que es común y cómo ellas reconfiguran lo sensible de una comunidad o cómo estas prácticas permiten la constitución de experiencias significativas. Entonces para pensar cuándo hay arte, más allá de sus producciones materiales, es necesario en primera instancia, pensar las maneras por las cuales estas prácticas vinculan actos de sensibilidad, y en segunda instancia, pensar, cómo estos actos pueden producir ciertas miradas, sean ellas críticas o no. En tercera instancia, se trata de analizar cómo estas prácticas constituyen un determinado pensamiento. Estos tres elementos resultan esenciales para situar las prácticas artísticas como formas de inscripción y de intervención particulares en una comunidad. Es por ello que el arte y la política se encuentran entrelazados en la constitución de órdenes, de regímenes, de visibilidades y de sensibilidades a través de las cuales las formas de repartición de lo sensible se manifiestan o pueden inscribir nuevos órdenes posibles.

Es ineludible indicar que el proceso de diferenciación y de separación del arte frente a otras esferas del pensamiento llega de manera compleja en la modernidad, puesto que fue necesario que dos condiciones aparentemente contradictorias se presentaran: de una parte, para obtener el estatus de arte fue indispensable que superara la condición de simple imagen, es decir que alcance su autonomía entre arte y no-arte. De otra parte, es necesario que se percibiera en el arte una cosa diferente, es decir un objeto distinto de un simple arreglo de un saber hacer, lo que constituye su heteronomía. Dicho de otro modo, el arte alcanza su autonomía en tanto arte, cuando se ve en él una cosa diferente a una imagen o cuando es algo más que un simple producto de un objeto bien hecho.

Proponiendo diferentes tipos de órdenes o regímenes de visibilidad, Rancière sugiere pensar tres regímenes de identificación del arte en Occidente. 
Así, incluso si se pueden dar elementos de tensión y de yuxtaposición entre uno u otro régimen, ellos establecen diferentes tipos de relación con la comunidad de sentido del cual hacen parte. La noción de régimen es aquí comprendida en el sentido clásico como una especie de comunidad o modo de organización. Al respecto, Aristóteles se refiere al régimen como un modo de agregación o modo de gobierno o incluso como modo de repartición de los lugares, de los espacios y de los tiempos, noción que es muy cercana a aquella empleada por Rancière. En esta dirección, los regímenes del arte manifiestan las formas de visibilidad de las jerarquías y las posiciones de los objetos y sujetos al interior de una comunidad. Es de este modo que un objeto artístico determinado puede ser visto como perteneciente a diversos regímenes, puede ser incluso portador de diferentes temporalidades. Así, un objeto pretendidamente contemporáneo puede reenviar a formas precedentes, del mismo modo que un objeto artístico moderno podría ser portador de otras formas en potencia y producir una ruptura respecto a las asignaciones de su propio tiempo.

Sin detenernos en cada una de las especificidades de los regímenes que establece el autor, señalamos que el paradigma discursivo del régimen ético se sitúa en la reflexión platónica sobre la imagen. Esta argumentación tiene una conexión específica con la divinidad, y por tanto existe una preocupación en relación - o no- al derecho de producir las imágenes dando origen a todos los episodios de censura que puede conllevar. Para Platón, no existe un arte en el sentido general, tampoco existe una definición de arte como un dominio separado de la vida o como un dominio apartado de la política. Las diferentes artes son más bien "modos de hacer", es decir, saberes que son apropiados por un sensorio común. Las imágenes concordantes con este régimen son aquellas que sirven a la educación y todas las otras imágenes no son más que meros simulacros, simples imitaciones de las apariencias que no esperan alcanzar un estatus de verdad. En este régimen, "la manera de ser de las imágenes concierne a un ethos, la manera de ser de los individuos y las colectividades" (Rancière, 2000, p. 28).

De manera diferente, en el régimen poético-representativo, se refuerza que el principio mimético es constitutivo de la naturaleza humana. La imitación, como bien sabemos, es una herramienta esencial que posee el artista creador. Este principio es del orden práctico en el sentido en que permite la separación de las artes de la imitación de las demás artes, al tiempo que admite una división global de las ocupaciones políticas y sociales. La consistencia del modelo de la mimesis no está ligada a la relación de similitud del objeto del cual es copia, sino al estatuto que es posible al interior de la imitación. Así, cada experiencia artística instituye una lógica según unos principios determinados y este aspecto es lo que prima en la determinación de su consistencia como obra de arte. En el régimen poético, las artes llegan a estar separadas de un saber hacer y al tiempo, son clasificadas según el uso de la palabra, el sonido, la imagen o el movimiento. Esta poética de identificación de las artes se llamará en la era clásica "bellas artes" (Rancière, 2000, p. 30). Bajo este régimen, es posible distinguir las buenas imitaciones de las malas en una visión que ordena las posiciones de los sujetos y de los objetos de una comunidad.

En el régimen estético del arte, al cual Rancière dedica una más extensa elaboración, los objetos del arte no son considerados como tales por una manera de hacer sino por un modo de ser sensible que es propio a los productos del arte. Este modo propio del arte presenta una ruptura con la normatividad del régimen de representación y se encuentra ligado a hacer ver los modos a través de los cuales los cuerpos, las prácticas y las experiencias del arte pueden tener un espacio-tiempo en un mundo común. Estos modos se separan también de las referencias a otras esferas de los saberes. Allí, los objetos y las experiencias artísticas se identifican como propias según un régimen específico de lo sensible: las prácticas del arte se separan del resto de las experiencias de la vida ordinaria y los objetos de arte son distinguidos del resto de objetos del mundo. Su singularidad consiste en la distinción del resto de cosas mundanas. Según Rancière, es una repartición sensible que se sustrae de sus conexiones ordinarias y que es habitado por una potencia heterogénea. Para el filósofo, la especificidad de este régimen es precisamente esta potencia de un sensible que deviene extraño a sí mismo. La paradoja de este régimen es, sin embargo, la de constituir una singularidad sensible del arte pero también destruir todo criterio a partir del cual ella puede ser delimitada. 


\section{El arte transformado en vida}

Dentro del régimen estético del arte, el sentido de una obra de arte o una práctica artística es que contiene una clave de inactividad, de distanciamiento en relación a una finalidad. El espectador, se abre al libre juego que produce la experiencia estética que a su vez consiste en un tipo especial de suspensión, incluso de abandono de un poder. La apariencia libre se presenta como distante, incluso inaccesible en su pura ociosidad, tanto el sujeto como el objeto en el encuentro se neutralizan en un sensorio específico que suprime las oposiciones entre actividad y pasividad.

La política del arte, bajo esta experiencia busca, sin embargo, alcanzar un determinado ethos de la comunidad, por el cual el arte puede cumplir una función específica: la educación. La estética promete así un espacio reconciliado a través de la construcción de un mundo sensible común. De este modo, la autonomía del arte y la promesa política de la libertad no se yuxtaponen, puesto que gracias a la experiencia estética se llegaría a una vida colectiva que no se encuentra ahora fragmentada. El arte permitiría una nueva educación que significaría que la experiencia estética alcanzaría aquello que por la vía exclusiva de la política no se consigue, es decir "la nueva configuración de un mundo común" y es en esto que consiste la revolución estética (Rancière, 2002).

A lo largo de varios textos, Rancière muestra distintos modos en los que se ha dado esta promesa; un ejemplo frecuente es cuando se unió la vanguardia artística con los movimientos revolucionarios comunistas hacia la década de 1920. Se trataba de pensar nuevas formas de vida, al tiempo que se pensaba la auto-supresión de la política como paralela a la supresión del arte. En este sentido, cuando la revolución estética asume la forma de una revolución humana, la lógica original se invierte: la ociosidad de la libre apariencia que había prometido una nueva igualdad se convierte ahora en el cumplimento de la promesa en donde el sujeto se aparta de la mera apariencia, que era el sueño de algo que ahora detenta en realidad (Rancière, 2002, p. 123).

Los ejemplos radicales de esta conversión de arte en vida pasan por las propuestas como la de Arts \& Crafts que oponen una producción de una serie de trabajos creativos y artesanales y en donde se busca volver al trabajo manual como sello de una verdadera originalidad. William Morris, fue uno de los primeros en declarar que un mueble bien diseñado es aquel que proporciona un buen descanso, en lugar de satisfacer las fantasías pictóricas de su propietario (Rancière, 2002, p. 123).

Otros proyectos se ubican en esta línea de fusión entre el diseño industrial y arte, en donde, ante todo, se trata de crear formas para habitar un mundo común. Es conocido que el proyecto de la Bauhaus fue un programa que buscaba esa conciliación de las bellas artes y las artes aplicadas. Sin embargo, se puede afirmar que la promesa de un arte transformado en vida a través del diseño tendió a subyugarse a los dictados del mercado. Es difícil entonces no encontrar los límites de la política que intenta reconectar el arte con la vida.

El problema no son las promesas liberadoras de las vanguardias sino comienza con las demandas de la industria y del mercado. El diseño hoy toma la forma consensual de nuestro tiempo, puesto que a menudo se somete a las dictaduras del deseo a tal punto que ya no es importante la satisfacción de las necesidades a través de los productos, sino esa imposición de un nuevo objeto puesto para ser inmediatamente consumido. La postura de Rancière sostiene mantener esa tensión entre autonomía y heteronomía. Es decir que, independientemente del proyecto de emancipación, el arte debe mantener una cierta distancia respecto de una vida estetizada. $Y$ es por ello tal vez la necesidad de volver a repensar la vanguardia en tanto momento de insistencia en la autonomía del arte, pero también una autonomía en tensión con la heteronomía.

\section{Las políticas del arte posutópico}

Finalmente, podemos abordar el problema de la reconstitución de la relación entre arte y política mirando algunas prácticas que nos permiten aproximarnos a las políticas del arte que Rancière llama posutópico. Aquí, las pretensiones de transformación y de revolución estética de la actualidad se presentan bajo formas que son mucho más modestas, es decir, distintas de las pretensiones radicales de las vanguardias que se moderan hacia versiones menos utópicas. Sin embargo, Rancière sostiene 
que no existe una separación radical entre la utopía vanguardista y la posutopía del presente; así, en el discurso a menudo se diga que hemos terminado con las utopías vanguardistas, es decir, tanto con una práctica de ruptura radical como con un discurso que pueda operar una transformación de las condiciones de la vida colectiva.

La consigna de terminar con las utopías se convierte en paradoja: hemos supuestamente superado las utopías de transformación pero continuamos con formas modestas de un arte que, a su manera, quiere cambiar el mundo. Esta paradoja de la utopía como forma modesta parece ser la versión del arte posutópico que se podría comparar con ciertas formas de política que ya no buscan una transformación radical.

La política de un arte posutópico busca más bien crear situaciones en donde es posible transformar nuestra mirada sobre el entorno colectivo. Al respecto, Rancière señala por lo menos dos formas de esta política, la primera ligada a un radicalismo del arte, en el sentido de una potencia de inscripción que rompe con la experiencia ordinaria. $Y$ una segunda, la forma modesta que ya no busca la transformación del mundo. La primera puede situarse como ligada a la teorización del concepto de lo sublime asociada al filósofo Jean-François Lyotard, mientras que la segunda se liga al campo profesional del arte y en particular a las prácticas de los años 90, que encarna, entre otras, la postura del curador Nicolas Bourriaud (2006).

En las dos posturas existe una apuesta fundamental: el arte realiza reconfiguraciones del espacio y del tiempo o invita a la creación de espacios perceptuales y de pensamiento diferentes. Mientras la primera política promulga por una potencia del arte ligada a su radical distancia en relación a la experiencia ordinaria; la segunda política propone formas de micropolítica, semejantes a aquellas de las políticas de la proximidad que a veces promulgan algunos políticos. El filósofo sostiene que estas dos políticas no oponen de manera simple un "arte por el arte" a un "arte comprometido", no se trata de escoger entre una política o la otra, sino más bien de cuestionar lo que "ellas testimonian y qué las hace posibles". Incluso, si Rancière a menudo vuelve sobre la primera política, que es aquella de la singularidad de la inscripción de ciertas obras en un museo y de su potencia como presentación de lo irrepresentable que escapa a toda conceptualización, creemos que la segunda política es la que más ha dado de que hablar en particular por su distancia y cercanía con la posición de los artistas de los años 90.

La referencia a una micropolítica aparece por ejemplo, en una exposición realizada en el año 2000 por el curador y teórico Paul Ardenne y la curadora Christine Macel. En la exposición, las microsituaciones hacen referencia a los artistas que presentan un rechazo frente a los dispositivos autoritarios bajo una forma que "ofrece un tema de reflexión más que una creencia, un trabajo preocupado por la escala humana, sin pretensión de universalidad o de una verdad intangible"3. Los curadores señalan el carácter fragmentario o "molecular" de esta noción de micropolítica que retoman de Félix Guattari.

En la exposición se presentaban artistas que privilegiaban "Ios micro-agenciamientos", "las micro-acciones" o "las acciones locales", una práctica que se separa de todo eslogan o mandato militante. Son propuestas entendidas como líneas de fuga ${ }^{4}$, donde las prácticas muestran posibilidades abiertas de modificar los ritmos y los modos de vida (Ardenne, 2000, p. 62). Para Ardenne y Macel, los artistas de los años 90 han aprendido las lecciones de la forma como, durante los años 80 , el arte político fue recuperado; ahora ya no habría un deseo de querer denunciar una "verdad"; de este modo, el artista se aleja de los discursos de autoritarismo o de grandilocuencia y busca más bien conectarse con una realidad próxima. Es como si los artistas

\footnotetext{
3 Micropolitiques es realizada en el Centre National d'art contemporain Magasin, en Grenoble, [5 febrero-30 abril 2000] por los curadores: Paul Ardenne y Christine Macel. El texto curatorial es publicado en el texto L'art dans son moment politique : écrit de circunstance (Ardenne, 2000).

4 Durante durante los años 90 es frecuente encontrar referencias teóricas a Deleuze y Guattari en los catálogos de arte. Estas referencias se separan a menudo de los contenidos concretos de esta filosofía. Nociones como "rizoma", "líneas de fuga", "agenciamientos" resultaban esenciales al interior de las escuelas de arte. A veces su pertinencia era desproporcionada en relación con las prácticas concretas. En otros casos, cierta libertad de conceptualización deleuziana ha tenido como resultado la creación de verdaderos laboratorios de experimentación.
} 
tuvieran más consciencia de los riesgos de una mala interpretación o temor de caer bajo las consignas de dominación de la macropolítica. Según los curadores, los artistas buscan una renovación del concepto de política ${ }^{5}$ que marca el comienzo en el sentido más clásico de las acciones "con la ciudad", es decir con su "ser colectivo", superando la consigna de "marchar delante" propia del comunismo - o de la vanguardia - para adoptar aquella de "marchar con".

Tal vez, la posición más ampliamente debatida en este sentido es La estética relacional (Bourriaud, 2006) que se convirtió, en la década pasada, en el leitmotiv de las prácticas dichas políticas -o micropolíticas - , en muchos casos olvidando que otras teorizaciones semejantes tales como "arte contextual" o "arte participativo" circulaban mucho antes de la propia teorización de Bourriaud. Sin embargo, después de su aparición, no ha dejado de suscitar tanto actitudes de aceptación como de rechazo 6 . La crítica ha considerado que el impacto del trabajo teórico de Bourriaud puede congregar un cúmulo de propuestas bastante heterogéneas, y tal vez por ello se considera que tiene una postura débil desde el punto de vista teórico, plagado de referencias a autores de múltiples corrientes. De otra parte, los críticos de esta postura señalan que los enunciados de Bourriaud son poco consistentes y demasiado ligados a una generación específica de artistas asociados a la práctica curatorial de Bourriaud, lo que en cualquier caso puede resultar cierto al confirmar la trayectoria de la mayoría de los artistas que apoyaba Bourriaud y que hoy se encuentran plenamente instalados dentro del circuito más oficial del arte contemporáneo ${ }^{7}$.

La noción central de la estética relacional y tal vez por ello su conexión con la teorización de Rancière, es aquella del intersticio y sin embargo,

\footnotetext{
5 Ardenne propone una definición moderna del término de lo políitico como "aquello que comienza con la ciudad, su funcionamiento, su ser colectivo: en la perspectiva, no de "marchar delante" (el sentido de arkhein, término original designando la política como comandar) sino más bien como "marchar con"". (Ardenne, 2000, p. 265)

6 Para una síntesis de las diversas posiciones de los crítico de la estética relacional ver (Prado, 2011) y (Belenguer, 2012).

7 Ver al respecto (Baqué, 2006) o (Bishop, 2004).
}

esta noción es analizada de modo bastante general en el texto del curador francés, entendido como "un espacio para las relaciones humanas que sugiere posibilidades de intercambio distintas de las vigentes en este sistema, integrado de manera más o menos armoniosa y abierta en el sistema global" (Bourriaud, 2006, p. 16). Para el curador, el intersticio es lo que permite la proximidad y engendra espacios diferentes a aquellos que son producidos por los mass media o que se encuentran en las actividades de consumo privado. La estética relacional prefiere como horizonte comprehensivo la esfera de las interacciones humanas y su contexto social que se diferencia de los espacios de consumo privados o individuales. Esta estética muestra ciertas formas de socialización específica en donde son posibles diferentes tipos de encuentro. Según Bourriaud, serían los nuevos espacios de exposición los que crearían estos intersticios donde es posible contraer la lógica de velocidad que se impone en la vida cotidiana. Estos espacios privilegian los intercambios que no se relacionan con las formas de comunicación de la sociedad globalizada y sus dispositivos de control. De todas maneras, las obras que llaman la atención del curador son aquellas que invitan a una socialización participativa, en varios casos consensual.

Se puede decir que el consenso surge en estas prácticas cuando ellas buscan restablecer el sentido perdido de un mundo social o desarrollan una cohabitación en la reparación de las fallas de ese lazo, y por tanto, como hemos sido testigos durante la última década, varias de estas propuestas llevan por título "convivialidad", "hospitalidad" o "cohabitación". Así, la utopía de ayer es hoy expresada en términos de proximidad.

Estemos o no de acuerdo con la estética relacional, lo cierto es que muchas de las exposiciones y publicaciones de la pasada década han convergido sobre estas nociones en conexión más o menos directa con la propuesta teórica de Bourriaud. El problema, a nuestro modo de ver, de la estética relacional es que está demasiado marcada por las categorías del consenso, incluso si declara volver sobre el sentido perdido de un mundo común: la mayoría de obras relacionales se encontraban en consonancia con las transformaciones de los museos de arte contemporáneo y particularmente con la política de promoción de 
los centros de arte conocidos como empresas de producción de servicios. La forma relacional en las exposiciones a menudo se transforma en espacios para el descanso al interior de las bienales o llama a eventos artísticos en donde pocos asisten.

Como bien lo ha señalado la historiadora Claire Bishop (2004), el problema de la estética relacional, incluso si tiene en cuenta el lazo social sobre el cual es necesario trabajar, es la forma en que lo realiza, que a menudo se queda en un espacio transitorio que no evidencia los antagonismos propios del encuentro de heterogéneos. Es por ello que siempre es necesario cuestionarnos sobre el sentido de los diálogos que promete esta estética.

El problema de la forma modesta no se sustenta solo en un juicio sobre la capacidad de transformar el mundo, sino en la necesidad de conformarnos con él; de igual modo que nos conformamos con una política modesta por miedo al antagonismo que supone a veces la confrontación de posiciones extremas. Si el lugar de la interacción relacional sucede solo en la exposición de arte, como sabemos la mayor parte del tiempo constituye solo un espacio que se da de manera forzada. Es de este modo que resulta pertinente el cuestionamiento de Bishop por los sujetos que pueden entrar tranquilamente a un museo o una galería y tener una conversación natural con un artista, es por ello que, necesariamente nos seguimos preguntando por aquellas obras menos consensuales e incluso por la posibilidad del arte como una práctica disensual.

$\star \star \star$

Como reflexión final, podemos resaltar que no todas las obras que trabajan con una comunidad y que intentan crear lazos sociales son consensuales. Lo que no significa que las obras que intensifican las relaciones humanas no puedan, bajo ciertas circunstancias, contribuir a la construcción y reparación de un lazo social, pero la creación de este lazo no es suficiente para que las obras sean políticas, menos aún disensuales. El riesgo de las prácticas relacionales, como hemos constatado durante la última década, es que a veces se convierten en una impostura sobre la creación de ese lazo que no podría, en ningún caso, palear una intervención política cuando existe por ejemplo una situación de inequidad.

La apuesta por un arte disensual —o una democracia de transformación radical-es que puede constituir comunidades polémicas capaces de someter al debate una situación determinada de distribución de los lugares y los espacios asignados. De este modo, podemos decir que el arte puede producir disenso, no por la declaración de un contenido político o de denuncia, o mediante una acción directa, sino por su manera de producir una ruptura del espacio sensible de lo común que redistribuye lo individual y lo colectivo o que distingue entre la apariencia y la realidad, produciendo otras formas de reconfiguración de la experiencia común. El arte es así político porque siempre introduce objetos y sujetos nuevos, o nos interroga sobre una acción incongruente y sobre todo porque no deja de proponernos temas nuevos para interrogar.

\section{Referencias}

Ardenne, P. (2000). L'art dans son moment politique: Ecrits de circonstance. Bruxelles: Lettre volée.

Baqué, D. (2006). Pour un nouvel art politique: de l'art contemporain au documentaire. Paris: Flammarion.

Belenguer, M. (2012). El presente de la estética relacional: hacia una crítica de la crítica. En Calle 14 revista de investigación en el campo del arte, 6(8), pp. 88-100.

Bishop, C. (2004). Antagonism and Relational Aesthetics. October, No. 110, pp. 3-30. https://doi. org/10.1162/0162287042379810

Bourriaud, N. (2006). Estética relacional. (C. Beceyro \& S. Delgado, Trads.). Buenos Aires: Adriana Hidalgo.

Game, J., \& Wald Lasowski, A. (2009). Jacques Rancière et la politique de l'esthétique. Paris: Éd. Des Archives contemporaines.

Jiménez, M. (2010). La querella del arte contemporáneo. Buenos Aires, Madrid: Amorrortu.

Maraniello, G. (2002). Art in Europe 1990-2000. Milan: Skira.

Prado, M. (2011). Debate crítico alrededor de la Estética Relacional. Recuperado 7 de abril de 2018, de «https://ddd.uab. 
cat/pub/disturbis/disturbis_a2011n10/disturbis_a2011n10a2/

Prado.html»

Rancière, J. (1996). El desacuerdo: política y filosofía. Buenos Aires: Nueva Visión.

. (2000). Le partage du sensible: esthétique et politique.

Paris (8 rue Saint-Roch, 75001): la Fabrique éd. https://doi.

org/10.3917/lafab.ranci.2000.01

(2002). La revolución estética y sus resultados.

New Left Review, No.14.

(2004). Malaise dans l'esthétique. Paris: Galilée.

(2009). Et tant pis pour les gens fatigués: entretiens. Paris:

Amsterdam

(2013). La haine de la démocratie. Paris: La fabrique

éditions.

Rancière, J., y Corcoran, S. (2015). Dissensus: on politics

and aesthetics. London: Bloomsbury.

Zourabichvili, F. (2007). El vocabulario de Deleuze.

Buenos Aires: Atuel. PMid:17697398 